\title{
Identification and proteomic profiling of exosomes in human cerebrospinal fluid
}

\author{
Jonathan M Street ${ }^{1}$, Perdita E Barran², C Logan Mackay², Stefan Weidt ${ }^{2}$, Craig Balmforth ${ }^{1}$, Tim S Walsh ${ }^{3}$,
} Rod TA Chalmers ${ }^{4}$, David J Webb ${ }^{1}$ and James W Dear ${ }^{r^{*}}$

\begin{abstract}
Background: Exosomes are released from multiple cell types, contain protein and RNA species, and have been exploited as a novel reservoir for disease biomarker discovery. They can transfer information between cells and may cause pathology, for example, a role for exosomes has been proposed in the pathophysiology of Alzheimer's disease. Although studied in several biofluids, exosomes have not been extensively studied in the cerebrospinal fluid (CSF) from humans. The objective of this study was to determine: 1) whether human CSF contains exosomes and 2) the variability in exosomal protein content across individuals.

Methods: CSF was collected from 5 study participants undergoing thoraco-abdominal aortic aneurysm repair (around $200-500 \mathrm{ml}$ per participant) and low-density membrane vesicles were concentrated by ultracentrifugation. The presence of exosomes was determined by western blot for marker proteins, isopycnic centrifugation on a sucrose step gradient and transmission electron microscopy with immuno-labelling. Whole protein profiling was performed using Fourier transform ion cyclotron resonance mass spectrometry (FT-ICR).

Results: Flotillin 1 and tumor susceptibility gene 101 (TSG101), two exosomal marker proteins, were identified in the ultracentrifugation pellet using western blot. These markers localized to a density consistent with exosomes following isopycnic centrifugation. Transmission electron microscopy visualized structures consistent with exosomes in size and appearance that labelled positive for flotillin 1. Therefore, the pellet that resulted from ultracentrifugation of human CSF contained exosomes. FT-ICR profiling of this pellet was performed and 84-161 ions were detected per study participant. Around one third of these ions were only present in a single study participant and one third were detected in all five. With regard to ion quantity, the median coefficient of variation was $81 \%$ for ions detected in two or more samples.
\end{abstract}

Conclusions: Exosomes were identified in human CSF and their proteome is a potential new reservoir for biomarker discovery in neurological disorders such as Alzheimer's disease. However, techniques used to concentrate exosomes from CSF need refinement to reduce variability. In this study we used relatively large starting volumes of human CSF, future studies will focus on exosome isolation from smaller 'real life' clinical samples; a key challenge in the development of exosomes as translational tools.

Keywords: Exosomes, human, CSF, proteomics

\footnotetext{
* Correspondence: james.dear@ed.ac.uk

'University/British Heart Foundation Centre for Cardiovascular Science, Queen's Medical Research Institute, The University of Edinburgh, Edinburgh, UK

Full list of author information is available at the end of the article
} 


\section{Background}

Exosomes are lipid and protein rich vesicles that are formed as part of the intra-cellular endosomal pathway [1]. During maturation of early endosomes into late endosomes within the cell, the endosomal limiting membrane undergoes invagination forming intra-luminal vesicles. A subset of endosomes fuse with the plasma membrane and their intra-luminal vesicles are released into the extracellular space where they are termed exosomes. Exosomes have physicochemical properties that distinguish them from other cell-derived vesicles. They are 20-100 $\mathrm{nm}$ in size [2], appear cup-shaped when visualised by transmission electron microscopy (TEM) [3], have a density of 1.10 to $1.19 \mathrm{~g} / \mathrm{ml}[4,5]$ and contain characteristic proteins that are central to their production [6]. Such proteins include flotillin-1, which is associated with lipid rafts that act as the location for exosomal formation [6] and tumor susceptibility gene 101 (TSG101), a component of the Endosomal Sorting Complex Required for Transport (ESCRT) protein group that mediates exosome assembly [7].

Exosomes represent a novel reservoir for biomarker discovery because they contain protein, messenger RNA and microRNA that has been demonstrated to change with the disease state of the affected organ $[8,9]$. To date, in the nervous system, most research into exosomes has been in vitro, for example, primary cultures of rat cortical neurons [10], differentiated cortical neurons [11] and glial cells [12,13] have been demonstrated to release exosomes. Using TEM and laser correlation spectroscopy, structures with a similar morphology to exosomes have been reported in human cerebrospinal fluid (CSF) $[14,15]$. The centrifugation fraction that expressed these structures on TEM contained the rasrelated protein Ral-A, a protein that has been associated with exosomes $[14,16]$.

In addition to being a source of biomarkers there is evidence that exosomes may mediate neurological disease. In Alzheimer's disease (AD), cleavage of amyloid precursor protein by the enzyme $\beta$-secretase occurs in a subset of endosomes and a fraction of the $A \beta$ protein is released into the extracellular milieu in association with exosomes $[17,18]$. Furthermore, exosomal markers are enriched in amyloid plaques from the brains of mice [19] and the post-mortem brains of patients with AD [17]. This suggests that exosomal transfer of amyloid into the extra-cellular space may be an important pathway in the development of AD. Extracellular accumulation of tau protein is another pathological hallmark of $\mathrm{AD}$. This protein is secreted in exosomes and an elevated CSF tau concentration in patients with $A D$ may be due to exosomal release from cells [20]. The protein $\alpha$-synuclein is a mediator of neurodegeneration in
Parkinson's disease (PD) that is released from cultured cells in exosomes [21]. Application of $\alpha$-synuclein containing exosomes onto cells induced cell death; consistent with exosomes being mediators of inter-cellular signalling, a physiological mechanism that has been reported in other organs [22,23]. Prion diseases are infectious neurodegenerative disorders and there is in vitro evidence that exosomes may represent the mechanism of prion protein transfer between cells $[24,25]$. In sheep CSF, prion proteins are enriched in exosomes [26]. Given their potential as a reservoir for biomarker discovery, and as mediators of neurological disease, the first objective of the present study was to confirm that human CSF contains exosomes.

The protein composition of a complex biofluid can be investigated using mass spectrometry [27-30]. This approach allows for an unbiased assessment of the proteome without the need for prior knowledge of protein identities. At present, there is no method for isolating exosomes from a complex biofluid without a degree of 'contamination' from non-exosomal proteins. Using quantitative mass spectrometry the second objective was to profile the composition of the human CSF sub-fraction that contained exosomes to give an indication of the variability and so provide information for planning future biomarker discovery studies.

\section{Methods}

\section{Study participants and sample collection}

CSF was collected from 5 patients undergoing thoracoabdominal aortic aneurysm repair. None of the patients had a history of neurological illness. This study was approved by NHS Lothian research ethics committee and prospective informed consent was obtained from all patients. This patient group was chosen because they have a CSF drain inserted peri-operatively as part of routine clinical management and large volumes of CSF are available for study (around $200-500 \mathrm{ml}$ ). Men were recruited to this study because female sex hormones may alter exosome release. The CSF was carefully inspected for evidence of blood contamination before collection. Protease inhibitors and preservative (final concentration: $3.34 \mathrm{mM}$ sodium azide, $0.5 \mathrm{mM}$ phenylmethylsulphonyl fluoride, $20 \mu \mathrm{M}$ leupeptin) were added to the collected CSF. The collected CSF was stored in aliquots at $-80^{\circ} \mathrm{C}$ before use [31].

\section{Exosome concentration}

After thawing, the CSF was vigorously vortexed then centrifuged at $15,000 \times g$ for 10 minutes to pellet any shed cells, large membrane fragments and other debris. The supernatant was then centrifuged at $200,000 \times g$ for 60 minutes. The pellet was resuspended in phosphate 
buffered saline (PBS) and then re-centrifuged at 200,000 $\times g$ for 60 minutes before final resuspension in PBS. The protein content of the exosomal fraction was determined using the BCA protein assay kit (Pierce, Rockford, IL, USA).

\section{Western blotting}

Samples were solubilised with Laemmli sample buffer and separated on a 1D SDS-PAGE gel before transfer to polyvinylidene fluoride (PVDF, Invitrogen, Paisley, UK) membrane. The membrane was probed with the following primary antibodies: mouse anti-human flotillin-1 (BD Biosciences, Franklin Lakes, USA) and mouse antihuman TSG101 (Abcam, Cambridge, UK).

\section{Sucrose density gradient}

Sample was diluted into the top fraction of a step gradient comprising layers of $2,1.3,1.16,0.8,0.5$ and $0.25 \mathrm{M}$ sucrose. The gradients were centrifuged for 2.5 hours at $100,000 \times g$. Six fractions were collected from the gradient and stored for density determination on a DMA 35 $\mathrm{N}$ density meter (Anton Paar, Hertford, UK) and for western blot analysis.

\section{Electron microscopy}

The exosomal fraction was mixed 1:1 with $4 \%$ paraformaldehyde. A drop of this solution was then placed on a Petri dish and a formvar-coated 200-mesh gold grid floated on top for 20 minutes. The grid was washed in PBS before low and high molecular weight blocking using $0.05 \mathrm{M}$ glycine/PBS and 1\% BSA/PBS, respectively. The grid was re-washed and transferred to a 1:200 dilution of the anti-flotillin- 1 antibody or the isotype control in $0.02 \%$ Triton X-100 PBS for 45 minutes at room temperature. The grid was then incubated with a $10 \mathrm{~nm}$ gold conjugated anti-mouse IgG antibody (Sigma Aldrich, Gillingham, UK) for 60 minutes at room temperature. The grid was washed again and incubated with $1 \%$ glutaraldehyde for 5 minutes. The grid was washed and then contrasted and embedded with $0.5 \%$ uranyl acetate $/ 2 \%$ methyl cellulose. Excess fluid was removed, the grid allowed to air dry and then the grid was examined on a Philips CM120 BioTwin transmission electron microscope.

\section{Proteomic analysis}

Proteomic studies were performed on the ultra-centrifugation pellet from each study participant, with each pellet being analysed in duplicate as per previous studies [32]. Initial studies demonstrated a high concentration of immunoglobulins in CSF. Therefore, after ultra-centrifugation, the immunoglobulins were depleted from the samples by incubation with protein $\mathrm{G}$ agarose beads (Fluka, Gillingham, UK). Depletion of immunoglobulin was confirmed by western blotting using an anti immunoglobulin primary antibody (AbD Serotec, Kidlington, UK). After immunoglobulin depletion, the presence of exosomes was confirmed by western blotting for flotillin-1.

\section{FT-ICR mass spectrometry}

The proteins present in the ultra-centrifugation pellet were separated from the lipid components using a chloroform/methanol precipitation [33]. Following resuspension of the chloroform/methanol precipitation pellet, separation was on a UltiMate 3000 series HPLC instrument (Dionex, Sunnyvale, CA, USA) equipped with a PS-DVB monolithic column $(500 \mu \mathrm{m} \times 5 \mathrm{~cm})$. Mass spectra were acquired on a $12 \mathrm{~T}$ Apex Ultra Qe FT-ICR mass spectrometer (Bruker Daltonics, Billerica, MA, USA), equipped with a electrospray source. Instrument control was achieved using Apex control. Each analysis was the average of 2 spectra. Ions were detected between $\mathrm{m} / z 200$ and 3000, yielding 1 Mword timedomain transients.

The mass spectrometry data was processed using the DataAnalysis (Bruker Daltonics, Billerica, MA, USA) software package version 4 SP4. The Progenesis LC-MS v2.6 software package (Non-linear Dynamics, Newcastle upon Tyne, UK) was used for the quantitative mass spectrometry. This package matched the peaks from the ion chromatograms of our 5 study participants by the elution time and $\mathrm{m} / \mathrm{z}$ ratio. The quality of the matching was checked manually. This matching process allowed determination of the number of samples which contained a given protein or peptide. The ion current was integrated over the elution window, then normalised against the total ion current of the chromatogram, and comparative quantitation of the abundance of an ion detected in 2 or more samples was calculated. Data analysis was performed in the python language with the Scipy http://www.scipy.org, and Matplotlib [34] packages used for general statistical analysis and data visualisation respectively.

\section{Results}

CSF was collected from 5 patients whose demographics are presented in Table 1. Ultracentrifugation of human

Table 1 Demographics and comorbidities for the 5 patients.

\begin{tabular}{llll}
\hline Patient & Sex & Age & Comorbidity \\
\hline 1 & $M$ & 67 & IHD and hypotension \\
\hline 2 & $M$ & 72 & Hypertension and CKD \\
\hline 4 & $M$ & 77 & Hypertension \\
\hline 5 & $M$ & 70 & DM and IHD \\
\hline
\end{tabular}

Abbreviations; IHD, Ischaemic heart disease; CKD, Chronic kidney disease; DM, Diabetes mellitus. 
CSF formed a pellet that contained protein (Figure 1a). Following separation of the proteins in the pellet there were bands unique to the ultracentrifuge pellet sample, suggesting that this may be a distinct proteome (Figure 1b). To investigate whether this proteome was, at least in part, exosomal in origin, the presence of established exosomal markers was determined using western blot for flotillin-1 and TSG101. This demonstrated enrichment of both proteins in the pellet compared with unfractionated CSF (Figure 1c). To further confirm that flotillin-1 and TSG101 were located in exosomes, isopycnic centrifugation on a sucrose step gradient was performed. Flotillin-1 and TSG101 localised to fractions 3 and 4, which corresponded to a density of 1.10-1.14 g. $\mathrm{cm}^{3}$ (Figure 1d). Isopycnic centrifugation was performed in 4 subjects and the exosomal markers were consistently localized to the density range $1.10-1.18 \mathrm{~g} . \mathrm{cm}^{-3}$ (data not shown).

TEM revealed a number of structures of exosomal size and appearance (Figure 2a) but there were also structures of a larger size, as has been previously reported [14]. To confirm that exosomes were present, labelling with an anti-flotillin 1 antibody was performed and cupshaped structures of the characteristic size for exosomes were found to bind gold nanoparticles (Figure 2b). When the flotillin-1 antibody was replaced with an

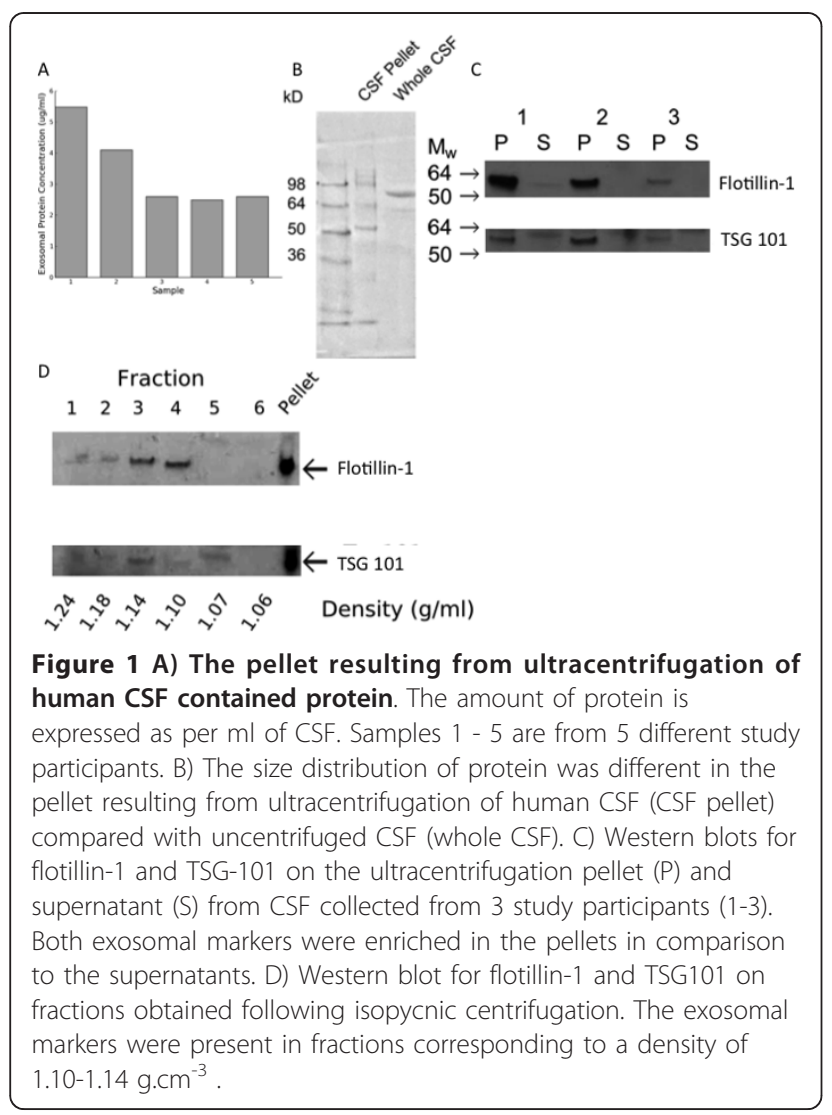

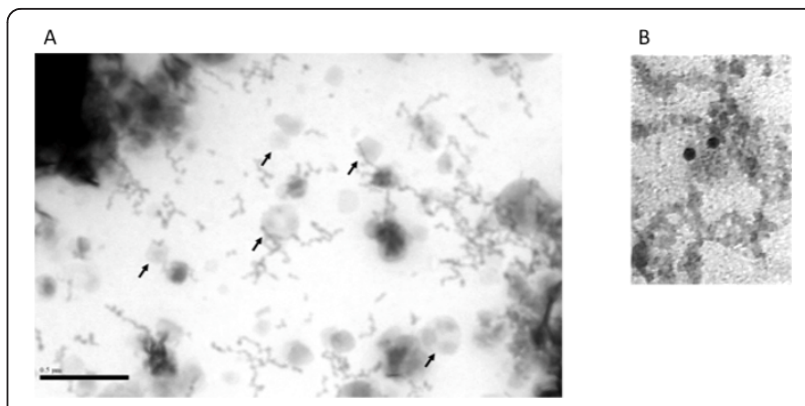

Figure 2 A) Transmission electron micrographs of embedded and negatively stained human CSF. Several structures of the characteristic size and appearance for exosomes are highlighted by arrows. B) Transmission electron micrographs of human CSF exosomes incubated with an anti-flotillin-1 antibody and then a gold nanoparticle tagged secondary antibody. A structure with the appearance of an exosome labelled by 2 gold nanoparticles is demonstrated in the figure.

isotype control antibody, although structures of the characteristic size and appearance could be identified, a significantly reduced number of bound gold nanoparticles were present (gold nanoparticle binding (mean \pm $\mathrm{SD}$ ): flotillin- 1 antibody $0.6 \pm 0.4$ particles per exosome; isotype control $0.1 \pm 0.1$ particles per exosome, $\mathrm{p}=$ 0.006 by t-test).

Profiling using FT-ICR MS detected between 84-161 ions in the 5 ultracentrifugation pellets (Figure 3a). The range of molecular weights were 636-33467 Da. Coefficient of variation $(\mathrm{CV})$ for the retention time was $0.13 \%$, facilitating the automated alignment performed by the Progenesis software. 66 ions were present in all 5 participants and 64 ions were only found in a single study participant (Figure 3b). For ions detected in two or more samples, the variability in the integrated ion current (a measure of an ion's abundance in a particular sample) across study participants was $68 \%$ at the $25^{\text {th }}$ percentile $(25 \%$ of ions had a $\mathrm{CV}<68 \%)$ and the median was $81 \%$ (Figure 3c). Among the ten most abundant ions the maximum variation was $13.9 \%$ (Table 2 ).

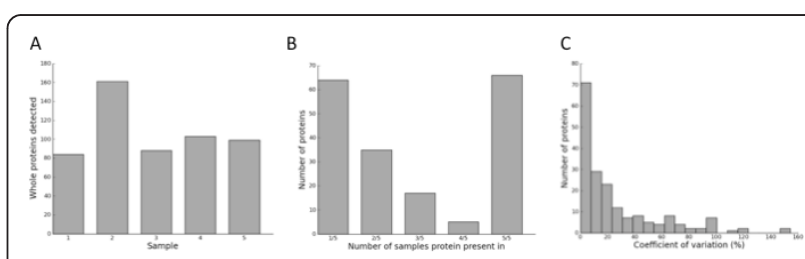

Figure 3 lons detected following FT-ICR MS on the pellet that resulted from ultracentrifugation of human CSF. A) The number of ions detected in each sample. Sample 1 - 5 are from 5 different study participants B) The number of ions detected in multiple samples. C) Histogram for the coefficient of variation of ions detected in 2 or more of the 5 CSF ultracentrifugation pellets. 
Table 2 The ten most abundant ions in the pellet that resulted from ultracentrifugation of human CSF as measured by FT-ICR MS.

\begin{tabular}{lllllllll}
\hline $\mathbf{m} / \mathbf{z}$ & Charge & Average Abundance & Coefficient of variation (\%) & \multicolumn{5}{c}{ Retention Time (min) } \\
\cline { 6 - 10 } & & & Retention 1 & Retention 2 & Retention 3 & Retention 4 & Retention 5 \\
\hline 659.5042 & 2 & 84905.83 & 9.48 & 32.35 & 32.34 & 32.44 & 32.41 & 32.39 \\
\hline 637.4901 & 2 & 79016.43 & 8.88 & 32.35 & 32.34 & 32.44 & 32.41 & 32.39 \\
\hline 681.5181 & 2 & 73538.83 & 10.40 & 32.35 & 32.34 & 32.44 & 32.41 & 32.39 \\
\hline 615.4762 & 2 & 71518.13 & 7.83 & 32.28 & 32.28 & 32.38 & 32.35 & 32.33 \\
\hline 703.5339 & 2 & 70627.72 & 10.75 & 32.42 & 32.40 & 32.51 & 32.47 & 32.44 \\
\hline 593.462 & 2 & 64351.47 & 9.18 & 32.28 & 32.28 & 32.38 & 32.35 & 32.33 \\
\hline 571.4479 & 2 & 51233.77 & 10.47 & 32.22 & 32.21 & 32.31 & 32.29 & 32.28 \\
\hline 725.5471 & 2 & 45044.52 & 9.20 & 32.42 & 32.40 & 32.51 & 32.47 & 32.44 \\
\hline 549.4341 & 2 & 41728.51 & 8.51 & 32.22 & 32.21 & 32.31 & 32.29 & 32.28 \\
\hline 527.42 & 2 & 29260.44 & 13.92 & 32.15 & 32.15 & 32.24 & 32.23 & 32.22 \\
\hline
\end{tabular}

Additional File 1 contains the whole dataset from FTICR MS.

\section{Discussion}

Release of exosomes from a variety of different neuronal cell lines has been described [10] and there is evidence that exosomes may be involved in the pathogenesis of neurological disease $[17,18]$. Despite the potential importance of exosomes in the context of the central nervous system and neurological diseases the presence of exosomes in human CSF has not been confirmed. In the present study we have demonstrated that exosomes are present in the CSF of humans. The evidence for exosome presence takes three forms: 1) proteins widely documented to be present within exosomes are enriched in the ultracentrifugation pellet in comparison with the supernatant; 2) following separation of the ultracentrifugation pellet based on density, the markers localise to a density range which is consistent with these proteins being contained in exosomes; 3 ) direct visualisation of the resuspended membrane vesicles from the ultracentrifugation pellet revealed the presence of structures matching exosomes in size and shape. In a further experiment these structures were demonstrated to contain the exosomal marker flotillin-1.

Exosomes are membrane bound vesicles formed within the cellular endosomal system [1] and released into a wide range of human biofluids such as blood [35], urine [2], ascites [36], amniotic fluid [37], pleural fluid [38] and saliva $[39,40]$. They contain protein, messenger RNA and microRNA [41] from their cell of origin which changes with cell activation and injury [42] and represents a reservoir for disease biomarker discovery. Exosomes also mediate inter-cellular communication by transferring protein and RNA species between cells and altering the recipient cell phenotype $[22,23]$. For example, in the immune system, exosomes transfer
microRNA from T-lymphocytes to antigen presenting cells and this microRNA modulates gene expression in the recipient cells [43]. The ability of the exosome to transfer information has been exploited to deliver systemically administered, short interfering RNA to the brain with a high degree of tissue-specificity [44]. In the present study we confirm the presence of exosomes in human CSF. This 'proof of concept' study should stimulate investigation of the differences between disease and control in terms of the exosome composition. Exosomes have been demonstrated to play a role in the pathogenesis of $\mathrm{AD}$ and an investigation of CSF exosomes from patients with AD is a potential next study. However, there are important caveats that need consideration before such a study can be successfully performed. In our study we recruited patients undergoing thoracoabdominal aortic aneurysm repair because this allowed access to large CSF volumes. Such volumes will not be available from patients with $\mathrm{AD}$ and so there is a need to refine our techniques for exosome isolation using approaches such as isopycnic centrifugation, ultrafiltration [45] or immunoaffinity [46]. In comparison to protein, the study of RNA has the advantage that amplification techniques are available and this may allow human CSF exosomal RNA to be studied with routinely available CSF volumes. As proof of concept, exosomes in human amniotic fluid, saliva and urine have been demonstrated to contain sufficient RNA to determine the presence of single nucleotide polymorphisms [37]. Finally, as the cellular origin of the exosomes is unknown, we do not know whether the cells affected by AD actually release exosomes into human CSF.

The human CSF exosomes were concentrated by ultra-centrifugation. This technique does not completely isolate exosomes from other components of a complex biofluid and non-exosomal proteins may still be present. To reduce this contamination, immunoglobulins were 
depleted before analysis. Mass spectrometry based profiling of our 5 study participants was performed to begin the process of understanding the variability between ultracentrifugation pellets prepared from different people. When mass spectrometer generated ion currents are being compared, specific tags can be used to label proteins from different proteomes. The two most commonly used methods are isotope-coded affinity tags (ICAT) and isobaric tag for relative and absolute quantification (iTRAQ)[47]. Both these techniques involve additional cost, experimental steps and, potentially, the inclusion of additional errors. Also, comparison across 5 proteomes would be difficult due to limited numbers of distinct labels. Our approach was label-free, and this was possible because FT-ICR MS provided extremely high accuracy in the $\mathrm{m} / \mathrm{z}$ ratios, ensuring confidence in matching ions across samples [48]. We only detected low molecular weight ions, that probably represent polypeptide species and small proteins, because larger species were deliberately excluded from entering the chromatography column. This was necessary to prevent large proteins attaching and failing to elute. Around a third of ions were present in all 5 study participants but a similar number were only detected in a single sample. For ions that were detected in 2 or more samples, the coefficients of variation were approximately comparable to similar studies including one in the whole CSF [49]. The ions that were only detected in single samples may represent technical variability in sample preparation, contamination from non-exosomal proteins or true variability in exosomal composition. Improved techniques for exosome isolation may reduce the variability in the samples. In the present study the ultra-centrifugation pellet from each study participant was analysed in duplicate, the same number of technical replicates as performed in other studies that have used mass spectrometry to quantify differences in human CSF protein abundance [32]. Increasing the number of biological and technical replicates may increase the ion coverage and improve confidence that an observed difference in an ion represents a true difference in the exosomal proteome.

\section{Conclusions}

We have identified exosomes in the CSF from humans. These cell-derived particles represent a new reservoir for neurological disease protein and RNA biomarker discovery. However, the techniques used to concentrate exosomes from CSF need refinement to improve the quality of exosome isolation. In this study we used relatively large starting volumes of human CSF, future studies will focus on exosome isolation from smaller 'real life' clinical samples; a key challenge in the development of exosomes as translational tools.

\section{Additional material}

Additional file 1: Mass Spectrometry data. Whole dataset from FT-ICR

MS on human CSF exosomes.

\section{List of abbreviations}

AD: Alzheimer's disease; CNS: Central Nervous System; CSF: Cerebrospinal fluid; ESCRT-I: Endosomal Sorting Complex Required for Transport; FT-ICR: Fourier transform ion cyclotron resonance mass spectrometry; TEM: Transmission electron microscopy; TSG101: Tumor susceptibility gene 101.

\section{Acknowledgements}

This study was funded by Alzheimer's Research UK and the British Heart Foundation. We acknowledge the contribution of the British Heart Foundation Centre of Research Excellence Award and the financial support of NHS Research Scotland (NRS), through NHS Lothian. The authors wish to thank the BBSRC and EPSRC for funding for SW and CLM, the BBSRC, EPSRC, Scottish Funding Council and Universities of Glasgow and Edinburgh for funding research through the RASOR IRColl in Proteomic Technologies.

\section{Author details}

${ }^{1}$ University/British Heart Foundation Centre for Cardiovascular Science, Queen's Medical Research Institute, The University of Edinburgh, Edinburgh, UK. 'EastChem School of Chemistry, The University of Edinburgh, Edinburgh, UK. ${ }^{3}$ Royal Infirmary of Edinburgh, Critical Care, Edinburgh, UK. ${ }^{4}$ Royal Infirmary of Edinburgh, Vascular Surgery Service, Edinburgh, UK.

\section{Authors' contributions}

JMS isolated exosomes and performed density studies, TEM and mass spectrometry with supervision of JWD (for all studies) DJW (for exosome isolation), PB (mass spectrometry), CLM (mass spectrometry) and SW (mass spectrometry). CB performed immunoblotting on exosomes. TSW and RTAC identified and recruited patients and organised sample collection. All authors read and approved the final manuscript.

\section{Competing interests}

The authors declare that they have no competing interests.

Received: 9 September 2011 Accepted: 5 January 2012 Published: 5 January 2012

\section{References}

1. Thery C, Zitvogel L, Amigorena S: Exosomes: composition, biogenesis and function. Nat Rev Immunol 2002, 2:569-579.

2. Pisitkun T, Shen R-F, Knepper MA: Identification and proteomic profiling of exosomes in human urine. Proc Natl Acad Sci USA 2004, 101:13368-13373.

3. Thery C, Amigorena S, Raposo G, Clayton A: Isolation and characterization of exosomes from cell culture supernatants and biological fluids. Curr Protoc Cell Biol 2006, Chapter 3(Unit 3):22.

4. Keller S, Rupp C, Stoeck A, Runz S, Fogel M, Lugert S, Hager HD, AbdelBakky MS, Gutwein P, Altevogt P: CD24 is a marker of exosomes secreted into urine and amniotic fluid. Kidney Int 2007, 72:1095-1102.

5. Graner MW, Alzate O, Dechkovskaia AM, Keene JD, Sampson JH, Mitchell DA, Bigner DD: Proteomic and immunologic analyses of brain tumor exosomes. The FASEB Journal 2009, 23:1541-1557.

6. Thery C, Ostrowski M, Segura E: Membrane vesicles as conveyors of immune responses. Nat Rev Immunol 2009, 9:581-593.

7. Stoorvogel W, Kleijmeer MJ, Geuze HJ, Raposo G: The Biogenesis and Functions of Exosomes. Traffic 2002, 3:321-330.

8. Zhou H, Pisitkun T, Aponte A, Yuen PS, Hoffert JD, Yasuda H, Hu X, Chawla L, Shen RF, Knepper MA, Star RA: Exosomal Fetuin-A identified by proteomics: a novel urinary biomarker for detecting acute kidney injury. Kidney Int 2006, 70:1847-1857

9. Zhou H, Cheruvanky A, Hu X, Matsumoto T, Hiramatsu N, Cho ME, Berger A Leelahavanichkul A, Doi K, Chawla LS, et al: Urinary exosomal transcription factors, a new class of biomarkers for renal disease. Kidney Int 2008 74:613-621. 
10. Faure J, Lachenal G, Court M, Hirrlinger J, Chatellard-Causse C, Blot B, Grange J, Schoehn G, Goldberg Y, Boyer V, et al: Exosomes are released by cultured cortical neurones. Mol Cell Neurosci 2006, 31:642-648.

11. Lachenal G, Pernet-Gallay K, Chivet M, Hemming FJ, Belly A, Bodon G, Blot B, Haase G, Goldberg Y, Sadoul R: Release of exosomes from differentiated neurons and its regulation by synaptic glutamatergic activity. Mol Cell Neurosci 2011, 46:409-418.

12. Potolicchio I, Carven GJ, Xu X, Stipp C, Riese RJ, Stern LJ, Santambrogio L: Proteomic analysis of microglia-derived exosomes: metabolic role of the aminopeptidase CD13 in neuropeptide catabolism. J Immunol 2005, 175:2237-2243.

13. Wang S, Cesca F, Loers G, Schweizer M, Buck F, Benfenati F, Schachner M, Kleene R: Synapsin I is an oligomannose-carrying glycoprotein, acts as an oligomannose-binding lectin, and promotes neurite outgrowth and neuronal survival when released via glia-derived exosomes. J Neurosci 2011, 31:7275-7290.

14. Harrington MG, Fonteh AN, Oborina E, Liao P, Cowan RP, McComb G, Chavez JN, Rush J, Biringer RG, Huhmer AF: The morphology and biochemistry of nanostructures provide evidence for synthesis and signaling functions in human cerebrospinal fluid. Cerebrospinal Fluid Res 2009, 6:10

15. Filatov MV, Landa SB, Pantina RA, Garmai lu P: [Investigation of exosomes secreted by different normal and malignant cells in vitro and in vivo]. Klin Lab Diagn 2010, 35-43.

16. Gonzales PA, Pisitkun T, Hoffert JD, Tchapyjnikov D, Star RA, Kleta R Wang NS, Knepper MA: Large-Scale Proteomics and Phosphoproteomics of Urinary Exosomes. J Am Soc Nephrol 2009, 20:363-379.

17. Rajendran L, Honsho M, Zahn TR, Keller P, Geiger KD, Verkade P, Simons K Alzheimer's disease beta-amyloid peptides are released in association with exosomes. Proc Natl Acad Sci USA 2006, 103:11172-11177.

18. Sharples RA, Vella LJ, Nisbet RM, Naylor R, Perez K, Barnham KJ, Masters CL, Hill AF: Inhibition of \{gamma\}-secretase causes increased secretion of amyloid precursor protein C-terminal fragments in association with exosomes. The FASEB Journal 2008, 22:1469-1478.

19. Kokubo H, Saido TC, Iwata N, Helms JB, Shinohara R, Yamaguchi H: Part of membrane-bound A[beta] exists in rafts within senile plaques in Tg2576 mouse brain. Neurobiology of Aging 2005, 26:409-418.

20. Saman S, Kim W, Raya M, Visnick Y, Miro S, Jackson B, McKee AC Alvarez VE, Lee NC, Hall GF: Exosome-associated tau is secreted in tauopathy models and is selectively phosphorylated in cerebrospinal fluid (CSF) in early Alzheimer's Disease. J Biol Chem 2011, Published online.

21. Emmanouilidou E, Melachroinou K, Roumeliotis T, Garbis SD, Ntzouni M, Margaritis LH, Stefanis L, Vekrellis K: Cell-produced alpha-synuclein is secreted in a calcium-dependent manner by exosomes and impacts neuronal survival. J Neurosci 2010, 30:6838-6851.

22. Valadi $\mathrm{H}$, Ekstrom K, Bossios A, Sjostrand M, Lee Jل Lotvall JO: Exosomemediated transfer of mRNAs and microRNAs is a novel mechanism of genetic exchange between cells. Nat Cell Biol 2007, 9:654-659.

23. Street JM, Birkhoff W, Menzies RI, Webb DJ, Bailey MA, Dear JW: Exosomal transmission of functional aquaporin 2 in kidney cortical collecting duct cells. J Physiol 2011, 589:6119-6127.

24. Fevrier B, Vilette D, Archer F, Loew D, Faigle W, Vidal M, Laude H, Raposo G: Cells release prions in association with exosomes. Proc Natl Acad Sci USA 2004, 101:9683-9688

25. Vella $\sqcup$, Sharples RA, Lawson VA, Masters CL, Cappai R, Hill AF: Packaging of prions into exosomes is associated with a novel pathway of PrP processing. The Journal of Pathology 2007, 211:582-590.

26. Vella L, Greenwood DL, Cappai R, Scheerlinck JP, Hill AF: Enrichment of prion protein in exosomes derived from ovine cerebral spinal fluid. Vet Immunol Immunopathol 2008, 124:385-393.

27. Yan W, Apweiler R, Balgley BM, Boontheung P, Bundy $J \mathrm{~L}$, Cargile BJ, Cole S, Fang X, Gonzalez-Begne M, Griffin TJ, et al: Systematic comparison of the human saliva and plasma proteomes. Proteomics Clin Appl 2009, 3:116-134

28. Aebersold R, Mann M: Mass spectrometry-based proteomics. Nature 2003, 422:198-207.

29. de Souza GA, Godoy LM, Mann M: Identification of 491 proteins in the tear fluid proteome reveals a large number of proteases and protease inhibitors. Genome Biol 2006, 7:R72
30. Hu S, Loo JA, Wong DT: Human body fluid proteome analysis. Proteomics 2006, 6:6326-6353

31. Zhou H, Yuen PST, Pisitkun T, Gonzales PA, Yasuda H, Dear JW, Gross P, Knepper MA, Star RA: Collection, storage, preservation, and normalization of human urinary exosomes for biomarker discovery. Kidney Int 2006, 69:1471-1476.

32. Ogata Y, Charlesworth MC, Higgins L, Keegan BM, Vernino S, Muddiman DC: Differential protein expression in male and female human lumbar cerebrospinal fluid using iTRAQ reagents after abundant protein depletion. Proteomics 2007, 7:3726-3734.

33. Wessel D, Flugge UI: A method for the quantitative recovery of protein in dilute solution in the presence of detergents and lipids. Anal Biochem 1984, 138:141-143.

34. Hunter JD: Matplotlib: A 2D Graphics Environment. Computing in Science \& Engineering 2007, 9:90-95

35. Hawari Fl, Rouhani FN, Cui X, Yu ZX, Buckley C, Kaler M, Levine SJ: Release of full-length $55-\mathrm{kDa}$ TNF receptor 1 in exosome-like vesicles: a mechanism for generation of soluble cytokine receptors. Proc Natl Acad Sci USA 2004, 101:1297-1302.

36. Runz S, Keller S, Rupp C, Stoeck A, Issa Y, Koensgen D, Mustea A, Sehouli J, Kristiansen G, Altevogt P: Malignant ascites-derived exosomes of ovarian carcinoma patients contain CD24 and EpCAM. Gynecol Oncol 2007, 107:563-571

37. Keller S, Ridinger J, Rupp AK, Janssen JW, Altevogt P: Body fluid derived exosomes as a novel template for clinical diagnostics. J Transl Med 9:86.

38. Bard MP, Hegmans JP, Hemmes A, Luider TM, Willemsen R, Severijnen LA, van Meerbeeck JP, Burgers SA, Hoogsteden HC, Lambrecht BN: Proteomic analysis of exosomes isolated from human malignant pleural effusions. Am J Respir Cell Mol Biol 2004, 31:114-121.

39. Palanisamy V, Sharma S, Deshpande A, Zhou H, Gimzewski J, Wong DT: Nanostructural and transcriptomic analyses of human saliva derived exosomes. PloS One 2010, 5:e8577.

40. Michael A, Bajracharya SD, Yuen PS, Zhou H, Star RA, Illei GG, Alevizos I: Exosomes from human saliva as a source of microRNA biomarkers. Oral Dis 2010, 16:34-38

41. Mathivanan S, Simpson RJ: ExoCarta: A compendium of exosomal proteins and RNA. Proteomics 2009, 9:4997-5000.

42. Skog J, Wurdinger T, van Rijn S, Meijer DH, Gainche L, Sena-Esteves M, Curry WT, Carter BS, Krichevsky AM, Breakefield XO: Glioblastoma microvesicles transport RNA and proteins that promote tumour growth and provide diagnostic biomarkers. Nat Cell Biol 2008, 10:1470-1476.

43. Mittelbrunn M, Gutierrez-Vazquez C, Villarroya-Beltri C, Gonzalez S, SanchezCabo F, Gonzalez MA, Bernad A, Sanchez-Madrid F: Unidirectional transfer of microRNA-loaded exosomes from T cells to antigen-presenting cells. Nat Commun 2011, 2:282.

44. Alvarez-Erviti L, Seow Y, Yin H, Betts C, Lakhal S, Wood MJ: Delivery of siRNA to the mouse brain by systemic injection of targeted exosomes. Nat Biotechnol 2011, 29:341-345.

45. Rood IM, Deegens JK, Merchant ML, Tamboer WP, Wilkey DW, Wetzels JF, Klein JB: Comparison of three methods for isolation of urinary microvesicles to identify biomarkers of nephrotic syndrome. Kidney Int 2010, 78:810-816.

46. Chen C, Skog J, Hsu CH, Lessard RT, Balaj L, Wurdinger T, Carter BS, Breakefield XO, Toner M, Irimia D: Microfluidic isolation and transcriptome analysis of serum microvesicles. Lab Chip 2010, 10:505-511.

47. Street JM, Dear JW: The application of mass-spectrometry-based protein biomarker discovery to theragnostics. Br I Clin Pharmacol 2011, 69:367-378.

48. Marshall $A G$, Hendrickson $C L$, Jackson GS: Fourier transform ion cyclotron resonance mass spectrometry: a primer. Mass Spectrom Rev 1998, 17:1-35.

49. Paweletz CP, Wiener MC, Bondarenko AY, Yates NA, Song Q, Liaw A Lee AY, Hunt BT, Henle ES, Meng F, et al: Application of an end-to-end biomarker discovery platform to identify target engagement markers in cerebrospinal fluid by high resolution differential mass spectrometry. $J$ Proteome Res 2010, 9:1392-1401.

doi:10.1186/1479-5876-10-5

Cite this article as: Street et al: Identification and proteomic profiling of exosomes in human cerebrospinal fluid. Journal of Translational Medicine 2012 10:5. 